\title{
Living Cationic Polymerization of Benzyl Vinyl Ether and Its Block Copolymers with Narrow Molecular Weight Distribution
}

\author{
Sadahito Aoshima, Shigeyuki IwaSA, and Eiichi KobaYashi* \\ Department of Industrial Chemistry, Faculty of Science and Technology, \\ Science University of Tokyo, Noda, Chiba 278, Japan
}

(Received January 13, 1994)

\begin{abstract}
The living cationic polymerization of benzyl vinyl ether (BnVE) was achieved by the $\mathrm{CH}_{3} \mathrm{CH}(\mathrm{O} i \mathrm{Bu}) \mathrm{OCOCH}_{3}(\mathbf{1}) / \mathrm{EtAlCl}_{2}$ initiating system in the presence of added bases. The effects of polymerization temperature and solvent were investigated in detail. Polymerizations in the presence of ethyl acetate at below $0^{\circ} \mathrm{C}$ in a non-polar solvent (toluene or $\mathrm{CCl}_{4}$ ) gave living polymers with a narrow molecular weight distribution (MWD) $\left(\bar{M}_{w} / \bar{M}_{n} \sim 1.1\right)$. The $\bar{M}_{n}$ of the polymers increased in proportion to monomer conversion. The obtained living polymer was rich in isotacticity $(\sim 80 \%)$ by ${ }^{1} \mathrm{H}$ NMR analysis. Fast living polymerization also occurred in the presence of methyl chloroacetate to synthesize higher molecular weight poly(BnVE) than $\bar{M}_{n}=10^{5}$. Block copolymers were prepared by the sequential living polymerization of BnVE and isobutyl vinyl ether. Debenzylation of poly(BnVE) and its block copolymers was achieved by two methods [(A) $\mathrm{HBr}$ in toluene and (B) $\mathrm{Na}$ in liq. $\mathrm{NH}_{3}$ ] to give PVA and its block copolymers with a narrow MWD.
\end{abstract}

KEY WORDS Living Cationic Polymerization / Benzyl Vinyl Ether / Isobutyl
Vinyl Ether / Carbocation Stabilization / Narrow Molecular Weight
Distribution / Block Copolymer / Isotactic Polymer / Debenzylation Reaction
/ Poly(vinyl alcohol) / 1,2-Glycol Content /

Poly(vinyl alcohol) (PVA) is generally synthesized by the radical polymerization of vinyl acetate followed by saponification. ${ }^{1}$ Several investigations have also been reported to prepare the stereoregular PVA. For example, isotactic PVA was derived from poly(benzyl vinyl ether) ${ }^{2}$ or poly(trimethylsilyl vinyl ether $)^{3}$ obtained by the cationic polymerization of the corresponding vinyl ethers. Vinyl acetate derivatives such as vinyl trifluoroacetate, ${ }^{4,5}$ vinyl chloroacetate ${ }^{5}$ and vinyl formate $^{6}$ gave syndiotactic PVA. However, these cationic and radical polymerizations do not easily give the living polymer so far, because monomers with the polar substituents cause a variety of side reactions with propagation reactions.

Recently, the living cationic polymerization of various vinyl ethers initiated with $\mathrm{EtAlCl}_{2}$ in the presence of Lewis bases was investigated. ${ }^{7-10}$ This polymerization system was based on the concept of stabilization of unstable propagating carbocations by added bases. The obtained polymers showed very narrow molecular weight distribution (MWD) and $\bar{M}_{n}$ was controlled by the monomer conversion or the [monomer]/[initiator] ratio.

In this study, to synthesize PVA with a narrow MWD and its block copolymers, living cationic polymerization of benzyl vinyl ether (BnVE) was investigated. We focused on the following points: (i) adequate conditions for the living polymerization of BnVE, (ii) evaluation of stereoregularity of the polymers obtained in the living system, (iii) synthesis of PVA with a narrow MWD by debenzylation

* To whom all correspondence should be addressed. 
reaction, and (iv) syntheses of high molecular weight PVA and its block copolymers containing PVA units.

As an example of synthesis of living PVA precursors, aldol-group-transfer polymerization of silyl vinyl ethers was also reported, ${ }^{11}$ which involve sequential silyl aldol condensation. Though the method is effective for molecular weight control and the synthesis of block copolymers or polymers of new structures, the monomers are limited to silyl vinyl ethers. By using the method of this paper, we can get living PVA precursors from not only BnVE but also tert-butyl vinyl ether ${ }^{12}$ or silyl vinyl ethers. ${ }^{10}$

\section{EXPERIMENTAL}

\section{Materials}

BnVE was prepared by $\mathrm{Hg}\left(\mathrm{OCOCH}_{3}\right)_{2}-$ catalyzed transetherification between ethyl vinyl ether (Tokyo Kasei) and benzyl alcohol (Wako Pure Chemical) in the presence of molecular sieves $4 \mathrm{~A}$ at room temperature for $5 \mathrm{~h}^{13}$ The crude products were distilled under reduced pressure over sodium hydride and then over lithium aluminium hydride [yield: $38 \%$, bp $69.0^{\circ} \mathrm{C} / 10 \mathrm{mmHg}$ (lit. $69.0^{\circ} \mathrm{C} / 10 \mathrm{mmHg}$ ), ${ }^{2}$ purity: $\geq 99.9 \%$ by gas chromatography]. Commercial isobutyl vinyl ether (IBVE) (Tokyo Kasei) was washed with aqueous alkaline solution and water, and distilled twice over calcium hydride. Toluene, $\mathrm{CCl}_{4}, \mathrm{CH}_{2} \mathrm{Cl}_{2}$, and 1,2-dimethoxyethane (Tokyo Kasei) were purified by usual methods and distilled twice over calcium hydride just before use. $\mathrm{EtAlCl}_{2}$ (Nippon Aluminium Alkyls) was distilled under reduced pressure. Ethyl acetate and methyl chloroacetate (Tokyo Kasei) as added bases were distilled twice over calcium hydride. 1-(Isobutoxy)ethyl acetate (1) was prepared from IBVE and acetic acid (Tokyo Kasei) as previously reported, ${ }^{8}$ and distilled twice over calcium hydride under reduced pressure.

\section{Polymerization}

Polymerization was carried out in a glass tube equipped with a three-way stopcock at $-20^{\circ} \mathrm{C}$ to $+40^{\circ} \mathrm{C}$ under a dry nitrogen atmosphere. Each glass tube was baked at about $250^{\circ} \mathrm{C}$ for $5 \mathrm{~min}$ before use. Polymerization was initiated by addition of $\mathrm{EtAlCl}_{2}$ solution in hexane into a mixture of solvent, BnVE, ester additive, and cationogen 1 at the polymerization temperature. After a proper interval, polymerization was quenched with $0.3 \mathrm{wt} \%$ ammoniac methanol. The quenched reaction mixture was washed with dilute hydrochloric acid $(c a .0 .1 \mathrm{~N})$ and water to remove initiator residues, and neutralized. The polymers were recovered from the organic layer by evaporation of the monomer and solvent under reduced pressure and vacuum dried overnight. By these procedures, no side reactions such as scission of the side benzyl group and crosslinking occurred. Monomer conversion was measured by gravimetry of polymers.

\section{Preparation of PVA from Poly (BnVE)}

Method $\mathbf{A}^{2}$ : Dry $\mathrm{HBr}$ gas bubbled into a solution of $1.0 \mathrm{~g}$ of poly $(\mathrm{BnVE})$ in $100 \mathrm{ml}$ of dry toluene with a dry nitrogen carrier gas at a flow rate of $100 \mathrm{ml} \mathrm{min}^{-1}$ at room temperature. After $60 \mathrm{~min}$, a white precipitate appeared. $\mathrm{HBr}$ gas bubbling was continued until no increase in the amount of the precipitate was observed. After $6 \mathrm{~h}, \mathrm{HBr}$ was purged by bubbling dry nitrogen into the reaction mixture and the supernatant liquid was removed by decantation. The residual precipitate was immersed in $400 \mathrm{ml}$ of methanol overnight, washed with methanol, and dried in a desiccator under reduced pressure. PVA thus obtained was purified by reprecipitation from water to methanol. Yield: 78\%. Complete debenzylation was confirmed by ${ }^{1} \mathrm{H}$ NMR spectroscopy.

Method $\mathbf{B}^{14}$ : A solution of $1.0 \mathrm{~g}$ of poly(BnVE) in $10 \mathrm{ml}$ of 1,2-dimethoxyethane was added to $70 \mathrm{ml}$ of liquid ammonia containing $0.8 \mathrm{~g}$ of sodium at $-78^{\circ} \mathrm{C}$. After reaction for 
$3 \mathrm{~h}, 1.8 \mathrm{~g}$ of ammonium chloride were added and the blue color of the solution disappeared. Ammonia was evaporated overnight under nitrogen stream. Degassed $25 \mathrm{ml}$ of $6 \mathrm{~N} \mathrm{HCl}$ aq. were added to the residue with stirring under nitrogen atmosphere. The aqueous solution was poured into a large amount of methanol to give a white precipitate. The precipitate $(\sim 0.7 \mathrm{~g})$ was dissolved in $10 \mathrm{ml}$ of water and dialyzed with ion exchanged water for 3 days in a cellulose tube (Sankyo Chemical). Yield: $92 \%$. Complete debenzylation was confirmed by ${ }^{1} \mathrm{H}$ NMR spectroscopy.

\section{Quantitative Analysis of 1,2-Glycol Linkage \\ (Head-to-Head Configuration) $^{15}$}

A large excess of $20 \mathrm{ml}$ of $0.1 \mathrm{~N} \mathrm{HIO}_{4}$ aq., for oxidative decomposition of the 1,2-glycol structure of PVA, was mixed with a $20 \mathrm{ml}$ of aqueous PVA solution containing $0.8 \mathrm{~g}$ of the polymer $\left(\bar{M}_{n}=1.2 \times 10^{5}, \bar{M}_{w} / \bar{M}_{n}=1.12\right)$. After $1 \mathrm{~h}, 8 \mathrm{ml}$ of $10 \mathrm{wt} \%$ KIaq. were added and the solution was stirred for $10 \mathrm{~min}$. A part of the solution $(\sim 10 \mathrm{ml})$ was titrated by $0.05 \mathrm{~N}$ $\mathrm{Na}_{2} \mathrm{~S}_{2} \mathrm{O}_{3}$ aq. When the color changed from violet to light yellow, $1 \mathrm{ml}$ of $1 \mathrm{wt} \%$ cornstarch solution was added. The end point of the titration was that corresponding to color disappearance.

\section{Measurement \\ Molecular weight distribution (MWD) of the polymers was measured by size-exclusion chromatography (SEC) in chloroform at $40^{\circ} \mathrm{C}$ on a CCPD instrument (TOSOH) equipped with three polystyrene gel columns [TSK gel G-2000, 3000, and 4000; $8.0 \mathrm{~mm}$ (i.d.) $\times 300 \mathrm{~mm}$ each] and a refractive index detector. Number- average molecular weight $\left(\bar{M}_{n}\right)$ and poly- dispersity $\left(\bar{M}_{w} / \bar{M}_{n}\right)$ were calculated from SEC curves on the basis of polystyrene calibration. ${ }^{1} \mathrm{H}$ NMR spectra were recorded on a JEOL FX9OQ spectrometer in $\mathrm{CDCl}_{3}$ or DMSO- $d_{6}$, TMS standard.}

\section{RESULTS AND DISCUSSION}

Living Cationic Polymerization of BnVE

Polymerization in the Presence of Ethyl Acetate. Various vinyl ethers form living polymers by the $1 / \mathrm{EtAlCl}_{2}$ initiating system in the presence of an appropriate Lewis base. ${ }^{7-10}$ To examine the conditions for the living cationic polymerization of BnVE with an aromatic ring, $\mathrm{BnVE}$ was polymerized by $1 / \mathrm{EtAlCl}_{2}$ in toluene at $0^{\circ} \mathrm{C}$ in the presence of ethyl acetate, under similar conditions for the living cationic polymerization of the alkyl vinyl ether as IBVE.

Polymerization in the absence of ethyl acetate was so rapid as to give $90 \%$ conversion in $10 \mathrm{~min}$ (Figure 1). The product polymer exhibited a broad MWD $\left(\bar{M}_{w} / \bar{M}_{n}=2.24\right.$, conv. $90 \%$ ) as shown in Figure 2(A), indicating side reactions such as chain-transfer reactions to frequently occur in the course of polymerization. The addition of excess ethyl acetate remarkably slowed down the polymerization as shown in Figure 1. MWD of the obtained polymer was very narrow $\left[\bar{M}_{w} / \bar{M}_{n}=1.05\right.$, conv. $100 \%$; see Figure 2(B)]. These findings demonstrate the living cationic polymerization of BnVE under similar conditions as well as other alkyl vinyl ethers.

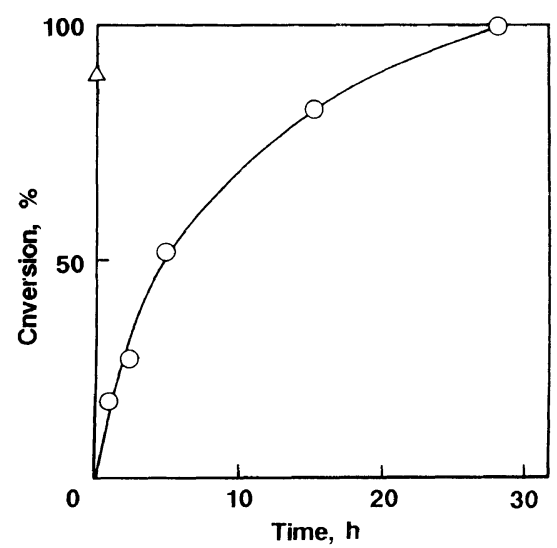

Figure 1. Time-conversion curves for $\mathrm{BnVE}$ polymerization by $\mathrm{l} / \mathrm{EtAlCl}_{2}$ in toluene at $0^{\circ} \mathrm{C}:[\mathrm{BnVE}]_{0}=0.72 \mathrm{M}$, $[1]_{0}=4 \mathrm{mM} ;\left[\mathrm{EtAlCl}_{2}\right]_{0}=20 \mathrm{mM}$; (O) $\left[\mathrm{CH}_{3} \mathrm{COOC}_{2} \mathrm{H}_{5}\right]$ $=1.0 \mathrm{M} ;(\triangle)$ without $\mathrm{CH}_{3} \mathrm{COOC}_{2} \mathrm{H}_{5}$. 
(A)

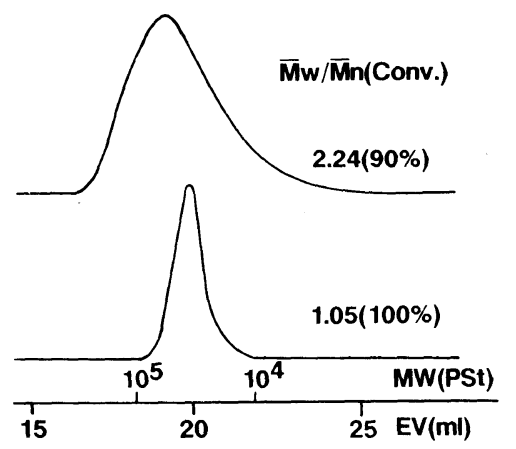

Figure 2. MWDs of poly(BnVE) obtained by $\mathrm{l} / \mathrm{EtAlCl}_{2}$ in toluene at $0^{\circ} \mathrm{C}$ in the absence $(\mathbf{A})$ and presence $(\mathbf{B})$ of ethyl acetate: $[\mathrm{BnVE}]_{0}=0.72 \mathrm{M} ;[1]_{0}=4 \mathrm{mM} ;\left[\mathrm{EtAlCl}_{2}\right]_{0}$ $=20 \mathrm{mM} ;\left[\mathrm{CH}_{3} \mathrm{COOC}_{2} \mathrm{H}_{5}\right]=1.0 \mathrm{M} \cdot \bar{M}_{w} / \bar{M}_{n}$ was estimated by SEC based on polystyrene standards.

\section{Effects of Polymerization Temperature and} Solvent. To clarify the effects of polymerization temperature, the polymerization of $\mathrm{BnVE}$ by $1 / \mathrm{EtAlCl}_{2}$ in the presence of ethyl acetate was carried out at $-20^{\circ} \mathrm{C}$ to $+40^{\circ} \mathrm{C}$. Polymerization rates increased with temperature. MWDs of the obtained polymers were very narrow $\left(\bar{M}_{w} / \bar{M}_{n}=1.05-1.06\right.$, conv. $\left.\sim 95 \%\right)$ at below $0^{\circ} \mathrm{C} . \bar{M}_{n}$ of the polymer increased with monomer conversion as shown in Figure 3.

At $+40^{\circ} \mathrm{C}$, MWDs of the obtained polymers became broader $\left(\bar{M}_{w} / \bar{M}_{n}=1.25\right.$, conv. $\left.90 \%\right)$ and $\bar{M}_{n}$ at the higher conversion $(>70 \%)$ deviated from a straight line, which was obtained from the polymerization at below $0^{\circ} \mathrm{C}$. The results demonstrate incomplete living polymerization at $+40^{\circ} \mathrm{C}$ even in the presence of ethyl acetate. It is concluded that the polymerization behavior of $\mathrm{BnVE}$ is somewhat different from that of IBVE which gave the living polymer even at $+40^{\circ} \mathrm{C}$.

For examination of the effects of solvent, polymerization in various solvents such as toluene, $\mathrm{CCl}_{4}$, and $\mathrm{CH}_{2} \mathrm{Cl}_{2}$ was also carried out in the presence of ethyl acetate at $0^{\circ} \mathrm{C}$. Figure 4 shows the relationship between the monomer conversion and $\bar{M}_{n}$ of the obtained polymers.

In toluene and $\mathrm{CCl}_{4}, \bar{M}_{n}$ of the obtained polymers increased linearly with monomer

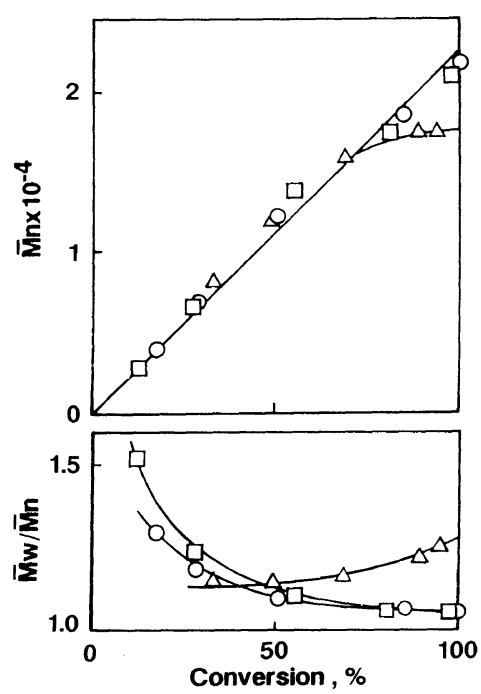

Figure 3. Relationship between monomer conversion and $M_{n}$ or $\bar{M}_{w} / \bar{M}_{n}$ ratio for BnVE polymerization by $\mathrm{l} / \mathrm{EtAlCl}_{2}$ in toluene in the presence of ethyl acetate: $[\mathrm{BnVE}]_{0}=0.72 \mathrm{M} ; \quad[\mathrm{I}]_{0}=4 \mathrm{mM} ; \quad\left[\mathrm{EtAlCl}_{2}\right]_{0}=20 \mathrm{mM}$; $\left[\mathrm{CH}_{3} \mathrm{COOC}_{2} \mathrm{H}_{5}\right]=1.0 \mathrm{M}$. Temperature: $(\square)-20^{\circ} \mathrm{C} ;(\mathrm{O})$ $0^{\circ} \mathrm{C} ;(\triangle)+40^{\circ} \mathrm{C} . \bar{M}_{n}$ and $\bar{M}_{w} / \bar{M}_{n}$ was estimated by SEC based on polystyrene standards.

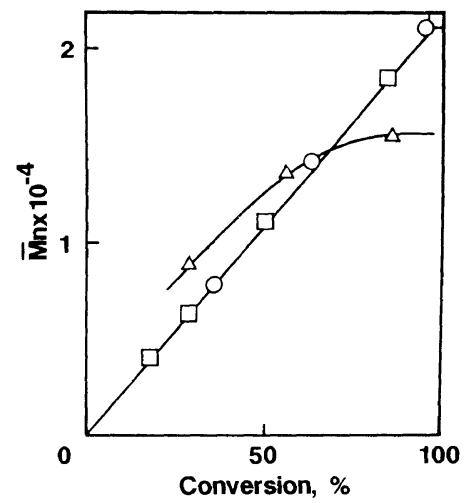

Figure 4. Relationship between monomer conversion and $\bar{M}_{n}$ for $\mathrm{BnVE}$ polymerization by $\mathrm{l} / \mathrm{EtAlCl} \mathrm{Al}_{2}$ at $0{ }^{\circ} \mathrm{C}$ in the presence of ethyl acetate: $[\mathrm{BnVE}]_{0}=0.72 \mathrm{M}$; $[1]_{0}=$ $4 \mathrm{mM} ; \quad\left[\mathrm{EtAlCl}_{2}\right]_{0}=20 \mathrm{mM} ; \quad\left[\mathrm{CH}_{3} \mathrm{COOC}_{2} \mathrm{H}_{5}\right]=1.0 \mathrm{M}$. Solvent: $(\square)$ toluene; (O) $\mathrm{CCl}_{4} ;(\triangle) \mathrm{CH}_{2} \mathrm{Cl}_{2} . \bar{M}_{n}$ was estimated by SEC based on polystyrene standards.

conversion. In sharp contrast, in the $\mathrm{CH}_{2} \mathrm{Cl}_{2}$ solvent, non-living polymerization was occurred, in which no linear increase of $\bar{M}_{n}$ was observed at higher conversion. From the above 
results, the appropriate selection of the temperature and solvent is indispensable to the living polymerization of BnVE.

Stereostructure and Debenzylation of Poly(BnVE)

Various physical properties of PVA depend on stereostructure. Thus, the tacticity of obtained poly(BnVE) with a narrow MWD, which reflects directly the tacticity of PVA $^{16}$ obtained by debenzylation, was evaluated by ${ }^{1} \mathrm{H}$ NMR analysis. In ${ }^{1} \mathrm{H}$ NMR spectra in $\mathrm{CDCl}_{3}$, the absorption of the methylene of the benzyl group showed three peaks attributed to triad tacticity. They were assignable to syndiotact $(\delta, 4.1 \mathrm{ppm})$, heterotact $(\delta, 4.2 \mathrm{ppm})$, and isotact $(\delta, 4.4 \mathrm{ppm})$ from the higher magnetic field. ${ }^{2}$ The polymer obtained $(95 \%$ yield, $\bar{M}_{n}=21000, \bar{M}_{w} / \bar{M}_{n}=1.09$ ) by $\mathbf{l} / \mathrm{EtAlCl}_{2}$ in the presence of ethyl acetate in toluene at $0^{\circ} \mathrm{C}$ for $48 \mathrm{~h}$ was rich in isotacticity: $81 \%$ of isotact, $15 \%$ of heterotact, and $4 \%$ of syndiotact by peak area of the three split peaks. Tacticity was almost identical with that in the non-living system. ${ }^{13}$ The influence of temperature, added bases, and counterions on stereoregularity was mentioned in the previous paper. ${ }^{17}$

To synthesize PVA with a narrow MWD, the debenzylation of the poly(BnVE) was carried out by the following two methods: the acid-hydrolysis by $\mathrm{HBr}(\operatorname{method} \mathbf{A})^{2}$ and reductive debenzylation by sodium in liquid ammonia (method B). ${ }^{14}$ In each case, water soluble PVA was obtained in good yield (see EXPERIMENTAL). In the ${ }^{1} \mathrm{H}$ NMR spectra of PVA obtained by methods $\mathbf{A}$ and $\mathbf{B}$, absorptions of the benzene ring $(7.0-7.2$ ppm) and side methylene group (4.1-4.5 ppm) of poly(BnVE) disappeared completely, and peaks assignable to the $\mathrm{OH}$ group were newly observed at $4.0-4.7 \mathrm{ppm}$ in DMSO- $d_{6}$ at $50^{\circ} \mathrm{C}$. The spectra did not exhibit peaks indicative of undesirable side reactions, e.g., oxidation of side benzyl groups or dehydration of obtained PVA. From the results, it is concluded that poly(BnVE) obtained by the living cationic polymerization changed completely to PVA.

The 1,2-glycol linkage (head-to-head configuration) of PVA can be quantitatively determined by $\mathrm{HIO}_{4}$ oxidation. ${ }^{15}$ As a sample, PVA $\left(\bar{M}_{n}=38000\right)$ prepared by the living cationic polymerization of $\mathrm{BnVE}(2.9 \mathrm{M})$ by $1 / \mathrm{EtAlCl}_{2}$ $(2 \mathrm{mM} / 4 \mathrm{mM})$ in the presence of methyl chloroacetate $(1.0 \mathrm{M})$ in $\mathrm{CCl}_{4}$ at $-20^{\circ} \mathrm{C}$ for $1.5 \mathrm{~h}$ (92\% yield, $\bar{M}_{n}=1.2 \times 10^{5}, \bar{M}_{w} / \bar{M}_{n}=1.12$; see next chapter) was used. It was found that the PVA contained about $0.1 \mathrm{~mol} \%$ 1,2-glycol linkage. This value is similar to that of PVA prepared by a conventional cationic
(A)

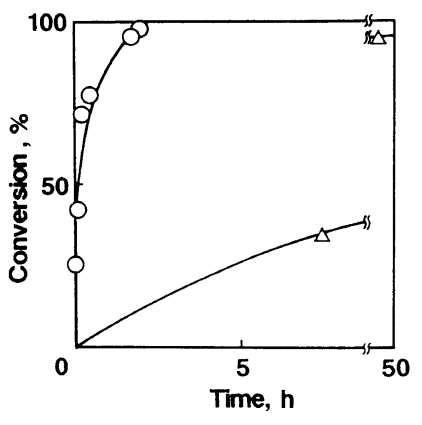

(B)

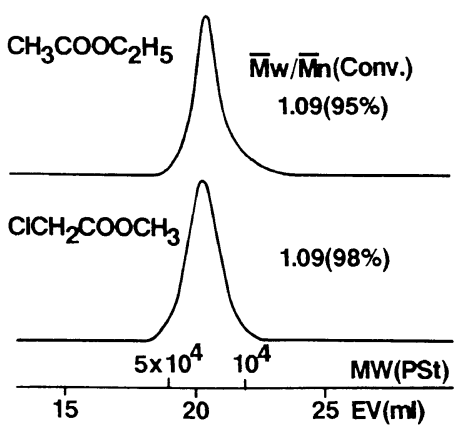

Figure 5. Time-conversion curves $(\mathbf{A})$ and $\mathrm{MWDs}(\mathbf{B})$ of the obtained polymers for BnVE polymerization by $\mathrm{l} / \mathrm{EtAlCl}_{2}$ in $\mathrm{CCl}_{4}$ at $0^{\circ} \mathrm{C}$ in the presence of an added base: $[\mathrm{BnVE}]_{0}=0.72 \mathrm{M},[1]_{0}=4 \mathrm{mM} ;(\mathrm{O})$ $\left[\mathrm{ClCH}_{2} \mathrm{COOCH}_{3}\right]=1.0 \mathrm{M}$ and $\left[\mathrm{EtAlCl}_{2}\right]_{0}=4 \mathrm{mM} ;(\triangle)\left[\mathrm{CH}_{3} \mathrm{COOC}_{2} \mathrm{H}_{5}\right]=1.0 \mathrm{M}$ and $\left[\mathrm{EtAlCl}_{2}\right]_{0}=$ $20 \mathrm{mM} . \bar{M}_{w} / \bar{M}_{n}$ was estimated by SEC based on polystyrene standards. 
polymerization of $\mathrm{BnVE},{ }^{16}$ but less than that $(1-3 \mathrm{~mol} \%)$ of PVA prepared by a radical polymerization of vinyl acetate. ${ }^{15}$
Syntheses of High Molecular Weight Poly(BnVE), Block Copolymers, and Its Derivatives Containing PVA Units

Since large polymerization rates are in-
(A)

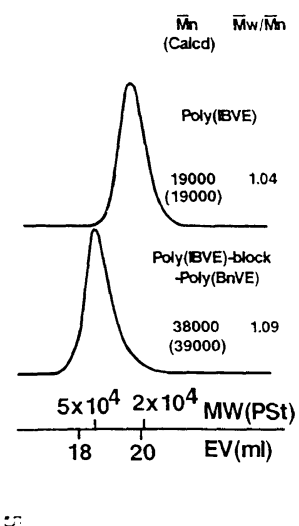

(B)

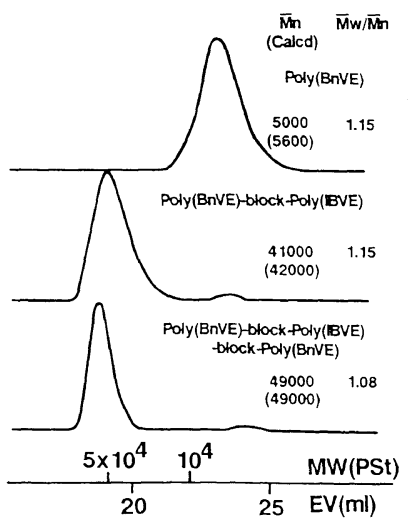

(C)

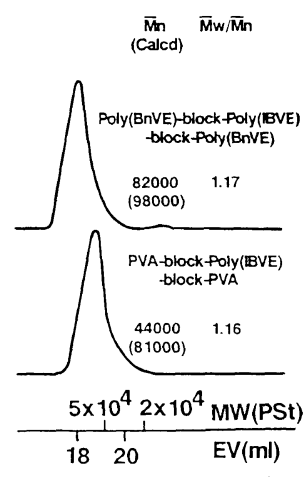

Figure 6. $\quad \bar{M}_{n}$ and $\bar{M}_{w} / \bar{M}_{n}$ of (A) diblock, (B) triblock copolymers, and (C) debenzylated triblock copolymer; $(\mathbf{A}),(\mathbf{B})$, and $(\mathbf{C}, \text { top })^{\mathrm{a}}$ were polymerized in $\mathrm{CCl}_{4}$ at $0^{\circ} \mathrm{C}$. Other conditions were as follows: $\bar{M}_{n}$ and $\bar{M}_{w} / \bar{M}_{n}$ was estimated by SEC based on polystyrene standards.

(A) Poly(IBVE)-block-poly(BnVE)

\begin{tabular}{|c|c|c|c|c|}
\hline & Monomer & Initiator & & Time \\
\hline & M & $\mathrm{mM} / \mathrm{mM}$ & $\left.{ }_{2} \mathrm{H}\right], \mathrm{M}$ & $\mathrm{h}$ \\
\hline $\begin{array}{l}\text { Starting } \\
\quad \text { poly(IBVE) }\end{array}$ & $\begin{array}{c}{[\mathrm{IBVE}]_{0}} \\
0.76\end{array}$ & $\begin{array}{c}{[1]_{0} /\left[\mathrm{EtAlCl}_{2}\right]_{0}} \\
4 / 20\end{array}$ & 1.0 & 8 \\
\hline $\begin{array}{l}\text { Diblock } \\
\text { copolymer }\end{array}$ & $\begin{array}{c}{[\mathrm{BnVE}]_{0}} \\
0.72\end{array}$ & & & 48 \\
\hline
\end{tabular}

(B) Poly(BnVE)-block-poly(IBVE)-block-poly(BnVE)

\begin{tabular}{|c|c|c|c|c|}
\hline & Monomer & Initiator & Added base & Time \\
\hline & M & $\mathrm{mM} / \mathrm{mM}$ & $\mathrm{CH}_{3} \mathrm{COOC}_{2} \mathrm{H}, \mathrm{M}$ & $\mathrm{h}$ \\
\hline $\begin{array}{l}\text { Starting } \\
\quad \text { poly }(\mathrm{BnVE})\end{array}$ & $\begin{array}{l}{[\mathrm{BnVE}]_{0}} \\
0.18\end{array}$ & $\begin{array}{c}{[1]_{0}\left[\mathrm{EtAlCl}_{2}\right]_{0}} \\
2 / 20\end{array}$ & 0.5 & 19 \\
\hline $\begin{array}{l}\text { Diblock } \\
\text { copolymer }\end{array}$ & $\begin{array}{c}{[\mathrm{IBVE}]_{0}} \\
1.52\end{array}$ & & & 21 \\
\hline $\begin{array}{l}\text { Triblock } \\
\text { copolymer }\end{array}$ & $\begin{array}{c}{[\mathrm{BnVE}]_{0}} \\
0.18\end{array}$ & & & 27 \\
\hline
\end{tabular}

a (C, top): Poly(BnVE)-block-poly(IBVE)-block-poly(BnVE) was polymerized under the same conditions as for $(\mathbf{B})$, except for $[1]_{0} /\left[\mathrm{EtAlCl}_{0}=2 \mathrm{mM} / 4 \mathrm{mM},\left[\mathrm{CH}_{3} \mathrm{COOC}_{2} \mathrm{H}_{5}\right]=0.5 \mathrm{M}\right.$; polym. time, $\mathrm{h}$; 13 (first state), 20 (second stage), 15 (final stage). 
dispensable to synthesize high molecular weight polymers, the fast living polymerization of BnVE was examined. Recently, we found that methyl chloroacetate having weaker basicity than ethyl acetate was effective as a base for the fast living polymerization of IBVE. ${ }^{10} \mathrm{BnVE}$ was polymerized in the presence of methyl chloroacetate by $1 / \mathrm{EtAlCl}_{2}$ in $\mathrm{CCl}_{4}$ at $0^{\circ} \mathrm{C}$. In the presence of methyl chloroacetate, polymerization proceeded at a higher rate than that in the presence of ethyl acetate as shown in Figure 5, in spite of small amount of $\mathrm{EtAlCl}_{2}$ $(4 \mathrm{mM})$ used as an activator. MWD of the obtained polymer was very narrow $\left(\bar{M}^{w} / \bar{M}_{n}=\right.$ 1.09 , conv. $98 \%$ ). The polymerization rate in the presence of methyl chloroacetate was tentatively evaluated as $4 \times 10^{2}$ times that in the presence of ethyl acetate, assuming that the rate increased with about second order of $\left[\mathrm{EtAlCl}{ }_{2}\right]{ }^{18}$

To synthesize higher molecular weight polymer than $10^{5}$, polymerization was carried out by $\mathrm{l} / \mathrm{EtAlCl}_{2}$ at a larger ratio of $[\mathrm{BnVE}]_{0} /[1]_{0}(2.9 \mathrm{M} / 2 \mathrm{mM}), \quad\left[\mathrm{EtAlCl}_{2}\right]_{0}=$ $4 \mathrm{mM}$ in $\mathrm{CCl}_{4}$ in the presence of methyl chloroacetate at $-20^{\circ} \mathrm{C}$. Polymerization proceeded to give $92 \%$ conversion for $1.5 \mathrm{~h} . \bar{M}_{n}$ of the obtained polymer was $1.2 \times 10^{5}$, and $\bar{M}_{w} / \bar{M}_{n}$ was 1.12 .

We were also interested in the block copolymer synthesis composed of hydrophilic crystallizable PVA units and hydrophobic rubbery poly(IBVE) units. Block copolymerizations of BnVE with IBVE were achieved by the living polymerization technique. Figure 6 shows typical results of IBVE-BnVE and BnVE-IBVE-BnVE block copolymers. In the case of diblock copolymerization [see Figure $6(\mathrm{~B})]$, at first IBVE was polymerized by the $1 / \mathrm{EtAlCl}_{2}$ initiating system in $\mathrm{CCl}_{4}$ in the presence of ethyl acetate at $0^{\circ} \mathrm{C}$ for $8 \mathrm{~h}$. To this solution was added $\mathrm{BnVE}$ and the $\mathrm{BnVE}$ monomer was completely polymerized for $48 \mathrm{~h}$. MWD of IBVE-BnVE block copolymer sifted toward higher molecular weight regions than that of the precursor poly(IBVE). No peaks were observed in the regions of the precursor poly(IBVE) and lower molecular weight oligomers made by side reactions. Using similar techniques, BnVE-IBVE-BnVE triblock copolymer with a narrow MWD was almost quantitatively obtained as shown in Figure 6(B), except for a trace amount of low molecular weight polymers at E.V. $23-24 \mathrm{ml}$ (Figure 6(B), middle and bottom).

With the quantitative reductive debenzylation reaction of the BnVE-IBVE-BnVE triblock copolymer of Figure 6 ( $\mathrm{C}$, top) by sodium in liquid ammonia, the triblock copolymer containing PVA and poly(IBVE) units was obtained, which was confirmed by ${ }^{1} \mathrm{H}$ NMR, IR $\left[3500 \mathrm{~cm}^{-1}(\mathrm{OH})\right]$ spectra, and MWD [Figure $6\left(\mathbf{C}\right.$, bottom)]. $\bar{M}_{n}$ (obsd) of the triblock copolymer containing PVA and poly(IBVE) units was much smaller than $\bar{M}_{n}$ (calcd), because the PVA unit in the polymer adsorbed to the polystyrene gel columns in SEC. ${ }^{19}$ Consequently, SEC of Figure 6 (C, bottom) gives only limited $\bar{M}_{w} / \bar{M}_{n}$ data.

PVA obtained by debenzylation of poly (BnVE) was soluble in water in which poly(BnVE) was insoluble, whereas PVA-blockpoly(IBVE)-block-PVA (number of units: $90: 760: 90)$ swelled in water. Solubility was measured on $1 \mathrm{wt} \%$ at room temperature. The syntheses of the block copolymers with various compositions and molecular weights, and physical properties such as viscoelasticity and tensile strength are now under investigation.

\section{REFERENCES}

1. I. Sakurada, "Poly(vinyl alcohol) Fibers," Marcel Dekker Inc., New York, N.Y., 1985.

2. H. Yuki, K. Hatada, K. Ota, I. Kinoshita, S. Murahashi, K. Ono, and Y. Ito, J. Polym. Sci., A-l, 7, 1517 (1969).

3. S. Murahashi, S. Nozakura, and M. Sumi, J. Polym. Sci., B3, 245 (1965).

4. H. Haas, E. S. Emerson, and N. W. Schler, J. Polym. Sci., 22, 291 (1956).

5. J. W. L. Foldham, G. H. McCain, and L. E. Alexander, J. Polym. Sci., 39, 335 (1959).

6. K. Fujii, S. Imoto, J. Ukita, and S. Matsumoto, 
Presented at the Symosium on High Polymers, Kyoto, Jpn., Nov., 1960.

7. S. Aoshima and T. Higashimura, Polym. Bull., 15, 417 (1986).

8. S. Aoshima and T. Higashimura, Macromolecules, 22, 1009 (1989).

9. Y. Kishimoto, S. Aoshima, and T. Higashimura, Macromolecules, 22, 3877 (1989).

10. S. Aoshima, K. Shachi, and E. Kobayashi, Makromol. Chem., 192, 1759 (1991).

11. D. Y. Sogah and O. W. Webster, Macromolecules, 19, 1775 (1986).

12. S. Aoshima, K. Shachi, and E. Kobayashi, Polym. J., 26, 335 (1994).

13. H. Yuki, K. Hatada, and K. Nagata, Bull. Chem. Soc. Jpn., 42, 3546 (1969).

14. W. H. H. Guntherand and M. N. Salzman, Ann. N. Y. Acad. Sci., 192, 25 (1972).
15. I. Sakurada and G. Takahashi, Gosei Sen-i Ronbunshu, 59 (1956).

16. S. Murahashi, H. Yuki, H. Tadokoro, K. Ono, Y. Ito, and $H$. Yasuhara, Proceeding, "The 3rd Symposium on Poly(vinyl alcohol)" (Daisankai Poly(vinyl alcohol), the Society of Polymer Science, Japan (Tokyo) and The Chemical Society of Japan (Tokyo) 1963, p 15.

17. S. Aoshima, Y. Ito, and E. Kobayashi, Polym. J., 25, 1161 (1993).

18. S. Aoshima, H. Onishi, and E. Kobayashi, Polym. Prepr. Jpn., 40, 758 (1991); S. Aoshima, H. Onishi, M. Kamiya, K. Shachi, and E. Kobayashi, J. Polym. Sci., A, Polym. Chem., 32, 879 (1994).

19. S. Murahashi, H. Yuki, T. Sano, U. Yonemura, H. Tadokoro, and Y. Chatani, J. Polym. Sci., 62, 174 (1962). 